\title{
Traction capabilities of a dual-voltage electric locomotive 2EV120 on the West Siberian Railway
}

\author{
Kirill Domanov ${ }^{1, *}$, Vasily Cheremisin ${ }^{1}$, and Anatoly Borodin ${ }^{1}$ \\ ${ }^{1}$ Omsk State Transport University, 644046, Marx av., 35, Omsk, Russia
}

\begin{abstract}
The paper discusses the traction parameters of an electric locomotive of a new generation. The existing schemes of sections served by electric locomotives and locomotive crews at the studied railway operating domain are presented. A comparison of the main parameters of DC and single-phase AC electric locomotives, the operation of which is currently organized at sections with trains of estimated weight in the longterm traction mode on the ground slopes with different steepness, is made. The scheme of the proposed organization of operation of dual-voltage electric locomotive and locomotive crews is presented. Traction parameters of a dual-mode electric locomotive are calculated, taking into account the plan and profile of the track at the proposed sections of operation, the specific basic resistance to the movement of the locomotive and the train at the estimated speed, the specific accelerating and decelerating forces of the train. When dual-mode electric locomotives are put into operation, it will be possible to reduce the fleet of locomotives in operation, the number of locomotive runs due to their lengthening, and the number of locomotive crew relief points, reduce the transit time of freight trains, increase technical and service speed, average daily mileage and average daily performance of the locomotive, reduce power consumption for traction. The operation of such electric locomotives contributes to the development of technologies for rail traffic management and the improvement of quantitative and qualitative indicators of various railway facilities.
\end{abstract}

\section{Introduction}

Improving the efficiency of the transportation process by railway transport depends on the integrated development of infrastructure. The most important elements of this system are the car fleet, tracks, power supply system, devices ensuring the safety of train traffic, the traction rolling stock that meets the modern technical requirements [1-2].

The most economically important direction of freight traffic in Russia is the KuzbassCenter transport corridor, part of which runs along the West Siberian Railway. Railway lines connect the largest basins of coal, ore, and hydrocarbons with the enterprises of the processing industry and land border crossing points. Forced technical stops for changing locomotives and locomotive crews at the junction stations of a DC electric traction with a

${ }^{*}$ Corresponding author: domanov35@gmail.com 
nominal voltage in a contact network of $3 \mathrm{kV}$ with switching to single-phase AC power supply with a nominal voltage in a contact network of $25 \mathrm{kV}$ with an industrial frequency of $50 \mathrm{~Hz}$ negatively affect the most important indicators of freight traffic [3-6].

Previously, a relatively small batch of domestic dual-voltage freight electric locomotives of the VL82M series with collector traction engines, which are still in operation on the electrified sections of the South, North Caucasus and October Railways, was produced for such sections. These electric locomotives outlived their usefulness, their traction and ergonomic characteristics do not correspond to the outlined in JSC "Russian Railways" vector of development of freight traffic or to the comfortable working conditions of locomotive crews. Nowadays, to increase the volume of traffic and increase the performance of railway transport, the relevance of the use of dual-voltage electric locomotives is increasing [7-9].

Improving the efficiency of the transportation process can be achieved by putting into operation innovative mainline dual-voltage freight electric locomotive 2EV120 "Prince Vladimir". An analysis of the possibility of putting this locomotive in operation first on the runs of Western Siberia shows that most of the railway lines are electrified with direct current, and only the Central Siberian route Artyshta II - Irtyshskoye is electrified with single-phase alternating current. At the same time, the southern route of the railroad consists of the electrified DC section Mezhdurechensk - Artyshta II (160 km long), bordering at Mezhdurechensk with the AC operating domain of the Krasnoyarsk Railway, the AC section Artyshta II - Irtyshskoye (840 km long) and the DC section Irtyshskoe Vkhodnaya (164 km long) with access to the DC operating domains of the South Ural and Sverdlovsk Railways (fig. 1). Thus, at the Mezhdurechensk - Vkhodnaya operating domain with a length of $1164 \mathrm{~km}$, there are three stations for jointing two types of current: Mezhdurechensk, Artyshta II, Irtyshskoye [10].

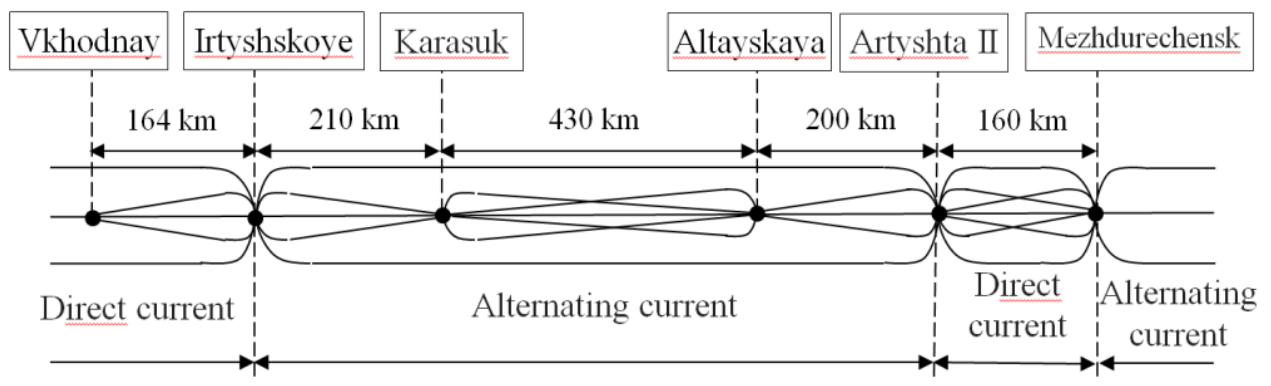

Fig. 1. The existing scheme of sections of operation of electric locomotives and locomotive crews at the operating domain Mezhdurechensk - Vkhodnaya.

Electric locomotives VL10, VL10U, VL11, 2ES6, 2ES10 operate at the DC sections of the Mezhdurechensk - Vkhodnaya section, and VL80TK and VL80S electric locomotives operate at the AC sections. The main parameters of these electric locomotives when driving in a long-term traction mode with trains of estimated weight on a slope with steepness of 8 $\%$ in comparison with the parameters of the electric locomotive 2EV120 are given in table $1-2$, where the following notation is used: $U_{e}-$ nominal voltage at the current collector, $k V$; $\mathrm{n}_{\mathrm{al}}$ - the number of axles of an electric locomotive; $\mathrm{m}_{1}$ - the weight of an electric locomotive, $\mathrm{t} ; \mathrm{V}_{\max }$ - maximum (design) speed, $\mathrm{km} / \mathrm{h} ; \mathrm{P}_{\mathrm{ed}}$ - rated electrical power of the traction motors, $\mathrm{kW} ; \mathrm{F}_{\mathrm{k}}$ - nominal tangential traction force, $\mathrm{kN} ; \mathrm{V}$ - rated speed, $\mathrm{km} / \mathrm{h} ; \mathrm{m}_{\mathrm{t}}$ the weight of the train, $\mathrm{t}$; $\mathrm{a}_{\mathrm{ed}}$ - specific energy consumption, $\mathrm{kW} \cdot \mathrm{h} / 10^{4} \mathrm{tkm}$.

Nowadays, for the organization of heavy traffic at sections with complex plan and profile of the track, the most common are electric locomotives of the 2ES10 "Granit", $1.5 \mathrm{VL} 10 \mathrm{~K}, 1.5 \mathrm{VL} 80 \mathrm{~S}$ series. In comparison with them, $2 \mathrm{EV} 120$ can drive trains, the 
weight of which reaches 9000 tons in gross, depending on the longitudinal profile of the track in two- and three-section design.

Table 1. The main parameters of electric locomotives when driving with trains of the estimated weight in the long-term traction mode on a slope with a steepness of $8 \%$.

\begin{tabular}{|c|c|c|c|c|c|c|c|c|c|}
\hline $\begin{array}{c}\text { Electric } \\
\text { locomotive } \\
\text { series }\end{array}$ & $\begin{array}{c}\mathrm{U}_{\mathrm{e}}, \\
\mathrm{kV}\end{array}$ & $\mathrm{n}_{\mathrm{al}}$ & $\mathrm{m}, \mathrm{t}$ & $\begin{array}{c}\mathrm{V}_{\max }, \\
\mathrm{km} / \mathrm{h}\end{array}$ & $\begin{array}{c}\mathrm{P}_{\text {ed, }} \\
\mathrm{kW}\end{array}$ & $\begin{array}{c}\mathrm{F}_{\mathrm{k},} \\
\mathrm{kN}\end{array}$ & $\begin{array}{c}\mathrm{V}, \\
\mathrm{km} / \mathrm{h}\end{array}$ & $\mathrm{m}_{\mathrm{t}}, \mathrm{T}$ & $\begin{array}{c}\mathrm{a}_{\mathrm{ed}}, \\
\mathrm{kW} \cdot \mathrm{h} / 10^{4} \\
\mathrm{~km}\end{array}$ \\
\hline VL10 & 3 & 8 & 184 & 100 & 4920 & 319 & 51,2 & 3285 & 292,5 \\
\hline $2 \mathrm{ES} 6$ & 3 & 8 & 200 & 120 & 6420 & 418 & 51,0 & 4355 & 289,1 \\
\hline $2 \mathrm{ES} 10$ & 3 & 8 & 200 & 120 & 9130 & 538 & 56,2 & 5625 & 288,8 \\
\hline VL80S & 25 & 8 & 192 & 110 & 6560 & 400 & 54,4 & 4143 & 291,0 \\
\hline 2 EV120 & $3 / 25$ & 8 & 200 & 120 & 10000 & 600 & 52,8 & 6336 & 298,9 \\
\hline
\end{tabular}

Gorky Railway, which is a part of the Kuzbass-Center transport corridor, is a pioneer in the organization of heavy traffic. Experimental trips with trains weighing 9000 tons carried out in 2007 on the Zyurzya - Vekovka section allowed introducing in 2010 a similar system of organizing the heavy train traffic on a number of other railroads of the network of JSC "RZD" [11].

Table 2. Ratios of the main parameters of electric locomotives when driving with trains of the estimated weight in the long-term traction mode on a slope with a steepness of $8 \%$.

\begin{tabular}{|c|c|c|c|c|c|c|c|c|c|}
\hline \multirow{2}{*}{$\begin{array}{c}\text { Electric } \\
\text { locomoti } \\
\text { ve series }\end{array}$} & \multicolumn{9}{|c|}{ Parameters } \\
\hline & $\mathrm{U}_{\mathrm{e}}$ & $\mathrm{n}_{\mathrm{al}}$ & $\mathrm{m}_{1}$ & $\mathrm{~V}_{\max }$ & $\mathrm{P}_{\text {ed }}$ & $F_{k}$ & V & $\mathrm{m}_{\mathrm{t}}$ & $\mathrm{a}_{\mathrm{ed}}$ \\
\hline$\frac{2 \mathrm{EV} 120}{\mathrm{VL} 10}$ & 1 & 1 & 1,087 & 1,2 & 2,033 & 1,881 & 1,031 & 1,929 & 1,022 \\
\hline$\frac{2 \mathrm{EV} 120}{2 \mathrm{ES} 6}$ & 1 & 1 & 1 & 1 & 1,558 & 1,435 & 1,035 & 1,455 & 1,034 \\
\hline$\frac{2 \mathrm{EV} 120}{2 \mathrm{ES} 10}$ & 1 & 1 & 1 & 1 & 1,095 & 1,115 & 0,94 & 1,126 & 1,035 \\
\hline$\frac{2 \mathrm{EV} 120}{\mathrm{VL} 80 \mathrm{~S}}$ & 1 & 1 & 1,042 & 1,091 & 1,524 & 1,5 & 0,971 & 1,529 & 1,027 \\
\hline
\end{tabular}

The most important indicators of electric locomotives in operation are the maximum weight of trains that they can drive at different sections, the speed on which the travel time depends, and the specific energy consumption for traction. Analysis of the data of table 1-2 shows that in the nominal long traction mode, due to the greater power and traction force, the electric locomotive 2EV120 can drive freight trains whose weight is 1.1-1.5 times more than for electric locomotives VL80S, 2ES6, 2ES10, and almost 2 times more than for the VL10 electric locomotive. At the same time, the speed of the electric locomotive 2EV120 differs by $3-6 \%$, and the specific energy consumption is $2-3 \%$ higher than for electric locomotives of the same type of current [10].

Due to the large length of the transport corridor under consideration, we have chosen a section that has a limiting gradient and the starting point for the formation of a freight train. A key element in determining the traction capabilities of an electric locomotive on a particular service run is the longitudinal profile of the track, which is the most difficult at the section Mezhdurechensk - Altayskaya. As a result of the analysis of the selected section, the hauls and sections with the worst conditions for the train traffic, which have limiting gradients, are identified. Artyshta II - Alambay became such a haul. In the calculations, the initial speed of $0 \mathrm{~km} / \mathrm{h}$ was taken from Artyshta II station. The calculations did not take into account multiple traction, pushing and the use of a booster mode. 


\section{Method for determining the parameters of a dual-voltage electric locomotive 2EV120 for train operation}

The considered section Artyshta II - Alambay has a length of $30 \mathrm{~km}$. It has 53 sections, 10 of which are not large slopes, and 43 sections are gradients, the maximum of which is equal to $9.1 \%$. During calculations and in order to take into account the length of a train when determining the forces acting on a train from slopes, the adjacent sections with nearly similar steepness and equal in sign of the elements of the real profile of the track are aligned. Slope steepness is determined by the formula [12]:

$$
i_{c}^{\prime}=\frac{\sum_{j=1}^{z} i_{j} l_{j}}{\sum_{j=1}^{z} l_{j}}=\frac{1}{l_{t}} \sum_{j=1}^{z} i_{j} l_{j}=\frac{10^{3}}{l_{t}}\left(h_{f}-h_{i}\right)
$$

where $\mathrm{z}$ - number of aligned elements;

$\mathrm{i}_{\mathrm{j}}$ - steepness of the $\mathrm{j}$-th element, \%o;

$\mathrm{l}_{\mathrm{j}}, \mathrm{l}_{\mathrm{t}}$ - the length of the $\mathrm{j}$-th element and the total length of the aligned elements, $\mathrm{m}$;

$\mathrm{h}_{\mathrm{f}}, \mathrm{h}_{\mathrm{i}}$ - final and initial altitude above the sea level of the aligned section, $\mathrm{m}$.

If there are curves in terms of the elements of the track on the aligned section, they are replaced with a fictitious gradient, the steepness of which is found using the expression (2):

$$
i_{c}^{\prime \prime}=\frac{1}{l_{t}} \sum_{j=1}^{z} w_{r j} l_{r j}
$$

where $\mathrm{w}_{\mathrm{rj}}$ - specific additional resistance to movement from the $\mathrm{j}$-th curve, $\mathrm{N} / \mathrm{kN}$;

$1_{r j}$ - the length of $j$-th curve, $m$;

$\mathrm{z}$ - the number of curves at the section.

The design gradient in determining the parameters of an electric locomotive for the implementation of train operation is the steepest and longest gradient at the studied section, where the locomotive realizes the design tangential traction force at a steady-state design speed. This gradient is chosen by analyzing the aligned and reduced profile of the track. At Artyshta II - Tyagun locomotive run, the steepest gradient is on the first haul to the Alambay station. It has a short length and there is a section in front of it with a light profile of the track, which allows the train to approach this gradient at high speed. It is not advisable to take such a gradient as a design one, since kinetic energy stored by a train can be used to overcome it.

Various forces will act on a train during its passage along the haul. The motion resistance forces are divided into the main ones, which always operate when the train is moving, and additional ones that arise only when moving along certain sections of the track or at certain periods of time. An important component in determining the traction capabilities of a dual-mode electric locomotive 2EV120 is the value of specific train motion resistivity $\mathrm{w}_{0}(3)$. It is determined at the design speed $\mathrm{V}$, depending on the type of track, using empirical formulas. For an electric locomotive, the main motion resistance under current is found. For cars, this value is determined depending on the type of cars, axle box bearings and weight per one axle of the car [12]. The Artyshta II - Alambay haul is a continuous welded rail track.

$$
\mathrm{w}_{0}^{\prime}=1,9+810^{-3} \mathrm{~V}+2,510^{-4} \mathrm{~V}^{2}
$$

Let us take into account that during the experimental trip, the train included the most popular on the network of JSC "RZD" four-axle freight cars with rolling bearings. The specific main motion resistance of such cars $\mathrm{w}^{\prime \prime}$ is determined using expression (4): 


$$
w_{c}^{\prime \prime}=0,7+\frac{3+0,1 \cdot V+0.0025 \cdot V^{2}}{m_{\text {c.a }}}
$$

where $\mathrm{m}_{\mathrm{c} . \mathrm{a}}$ - weight per car axle in laden condition equal to $22 \mathrm{t}$.

One of the most important components in carrying out traction calculations is the weight of the composition of the freight train cars. It is calculated (5) according to different criteria, based on the full use of power and traction qualities of an electric locomotive. First of all, the maximum weight of the composition $\mathrm{m}_{\mathrm{c}}$ is calculated according to the conditions of adhesion of wheels of an electric locomotive of weight $m_{l}$ with rails when moving in a steady-state traction mode with a design speed $\mathrm{V}$ and a tangential traction force $\mathrm{F}_{\text {t.p }}$ at the design gradient with steepness $i_{p}$.

$$
m_{c}=\frac{F_{t . p} \cdot 10^{3}-m_{l} g\left(w_{0}^{\prime}+i_{p}\right)}{g\left(w_{0}^{\prime \prime}+i_{p}\right)},
$$

for averaged adverse conditions of adhesion (wet rails, automatically or manually using sand if needed), the adhesion limit for the electric locomotive 2EV120, when operating on both alternating and direct current, is recommended to take using the formula for calculating the coefficient of adhesion on the rim of a wheel set (average for electric locomotive) [13-14]:

$$
\Psi_{\mathrm{K}}=0,31+\frac{4,5}{50+6 \cdot \mathrm{V}}-0,0006 \cdot \mathrm{V}
$$

This formula gives the values of the coefficient of adhesion, as compared with the Rules for traction calculations for electric locomotives with collector traction motors and contactor regulation of traction force:

- about 12\% higher than AC electric locomotives;

- about 19\% higher than DC electric locomotives.

In specific sections of operation of the electric locomotive 2EV120, the adhesion limit may differ from the recommended: higher, depending on the specific types of rail contamination (oil film, coal dust, etc.) [14].

The traction calculations consider only those terms of the total and specific forces applied to the train, which are directed along the train traffic line, since they affect the forward motion of the train along the track gauge. The specific force is the resistance force of each unit of weight of the train. Without values of specific accelerating and decelerating forces, it is impossible to solve the braking problem. These forces characterize the acceleration, as well as the deceleration of a train in various modes of movement at a straight horizontal section of the track. They are used in solving the equation of train motion. The specific accelerating force of the train of weight $\mathrm{m}$ in the traction mode is determined by the formula (7):

$$
\mathrm{f}_{\mathrm{y}}=\mathrm{f}_{\mathrm{K}}-\mathrm{w}_{0}=\frac{\mathrm{F}_{\mathrm{K}} \cdot 10^{3}}{\mathrm{mg}}-\mathrm{w}_{0}
$$

where $\mathrm{w}_{0}$ - the main specific resistance to the motion of the entire train, $\mathrm{kN}(8)$;

$\mathrm{F}_{\mathrm{K}}$ - values of traction force at running positions, $\mathrm{kN}$;

$\mathrm{m}$ - the weight of a train (the sum of $\mathrm{m}_{1}$ and $\mathrm{m}_{\mathrm{c}}$ ).

$$
w_{0}=\frac{w_{0}^{\prime} \cdot m_{l}+w_{c}^{\prime \prime} \cdot m_{c}}{m_{l}+m_{c}}
$$

It is advisable to calculate $f_{y}$ for the limiting lines and traction characteristics $F_{k}$ at the running positions of the voltage regulation of the traction motor with a speed interval of 5$10 \mathrm{~km} / \mathrm{h}$, including the design speed $\mathrm{V}$ and speed at other characteristic points [12]. 
We take in the calculations that the specific decelerating force of the train motion $f_{\text {d.v }}$ is equal to the main specific resistance of the train motion. Then the specific brake force of the train during emergency pneumatic braking will be found by the formula (9):

$$
b_{\mathrm{p} . \mathrm{b}}=1000 \cdot \varphi_{\mathrm{d} . \mathrm{c}} \cdot \vartheta_{\mathrm{d}},
$$

where $\varphi_{\text {d.c }}-$ design friction coefficient of brake pads;

$\vartheta_{\mathrm{d}}-$ design brake coefficient.

During a set of acceptance and certification tests of the dual-mode electric locomotive 2EV120 in October 2017, brake tests were the first to be carried out according to the schedule. Here, the developers of the electric locomotive got negative results in terms of nonconformance of the braking distance of emergency braking to the standards. Cast iron pads without flanges, previously used on the Czechoslovak electric locomotives of the CS series, were used on the dual-voltage electric locomotive "Prince Vladimir" since the moment of its production. At the end of the initial tests, it was found that the friction coefficient of the used pads does not match the design formula given in the Rules for traction calculations for standard cast iron pads with relatively low phosphorus content. This discrepancy led to an error in the design calculations of the brake force [13-14].

To eliminate the identified problem, it was necessary to increase the friction coefficient of the brake pads by increasing the concentration of phosphorus. An experimental batch of brake pads was manufactured at an electric locomotive repair plant in the city of Yaroslavl. The new pads were certified, as they showed a positive result during repeated tests. When carrying out calculations on the section of the Artyshta II - Tyagun haul under the study, the value of $\varphi_{\text {d.c }}$ depending on the speed for brake pads with high phosphorus content is determined using the expression (10):

$$
\varphi_{\text {d.c }}=0,30+\frac{V+100}{5 \cdot V+100} .
$$

The lowest value of the design braking coefficient $\vartheta_{\mathrm{d}}$ according to the norms of braking calculations for loaded freight trains with brake pads having a high phosphorus content and maximum speed on the studied section up to $80 \mathrm{~km} / \mathrm{h}$ is taken equal to 0.33 [12].

To solve the braking problem, it is necessary to determine the specific decelerating force of the train in the service pneumatic braking mode (11):

$$
\mathrm{f}_{\text {d.p.b }}=\mathrm{w}_{0}+\mathrm{k}_{\vartheta \mathrm{d}} \mathrm{b}_{\mathrm{p} . \mathrm{b}},
$$

where $\mathrm{k}_{\vartheta_{\mathrm{d}}}$ - the degree of use of the design braking coefficient at scheduled stops at separate points and checking the efficiency of automatic brakes for freight trains is 0.5 . When adjusting braking is used to maintain the set speed on the slopes, as a rule, the 1st stage of service braking is used, and the degree of use of the design braking coefficient for freight trains with loaded and average air distribution mode is taken equal to 0.3 .

While the train is driving by a machinist on the studied haul with sections of the track profile expressed as a descent, the electric braking mode can be used. In the dual-mode electric locomotive 2EV120, regenerative and dynamic electric braking is used. This mode affects the motion speed as a specific decelerating force during electric braking, which can be determined by the formula (12):

$$
f_{d . d}=b_{\kappa}+w_{0}=\frac{B_{\kappa}}{m g}+w_{0}
$$

where $b_{\kappa}$ - specific brake force of an electric brake of an electric locomotive, N/kN.

Calculation of $\mathrm{f}_{\text {d.d }}$ is performed for limiting lines and braking characteristics of an electric locomotive at all regulation positions with a speed interval of $5-10 \mathrm{~km} / \mathrm{h}$. 


\section{Results}

The most important standard of freight transportation is the implementation of the stated quantitative indicator expressed in done work (ton-kilometer), the implementation of which depends on train weight standards. According to the results of the calculations, we conclude that the 2EV120 "Prince Vladimir" electric locomotive can perform train operation at the Artyshta II - Altayskaya locomotive run in accordance with the train weight standard previously established by the order of the Deputy General Director of the JSC "RZD" Head of the Directorate of Traction Z-SIB TsT-108 dated May 30, 2017 "On the establishment of standards for the weights and lengths of passenger and freight trains at the sections served by the West Siberian Directorate of Traction" [15]. The dual-mode electric locomotive 2EV120 as a part of the train, the weight of which exceeds the critical one for trains with leading VL80S locomotives and ranges from 4,000 tons to 5,520 tons, can pass the sections with limiting gradients and requiring push locomotives without stops. In the three-sectional design, the electric locomotive 2EV120 on this locomotive run can drive trains weighing up to 7300 tons without pushing. Electric locomotives 1.5VL80S without pushing have train's weight restrictions of 5700 tons.

The dual-mode electric locomotive 2EV120 is equipped with a traction asynchronous drive. It is believed that it provides maximum performance of traction properties. On the electric locomotive, axial traction control and special control algorithms are used to increase the adhesion coefficient. According to the calculation results, the adhesion coefficient at the Artyshta II - Altayskaya locomotive run in the design mode is equal to 0.294 with the traction force in the design mode equal to $578 \mathrm{kN}$.

In the case of commissioning of the dual-voltage electric locomotive 2EV120 at the Mezhdurechensk - Vkhodnaya operating domain, it is possible to lengthen service sections of locomotive crews and instead of five get three locomotive runs: Mezhdurechensk Altayskaya (360 km long), Altayskaya - Karasuk (430 km long), Karasuk - Vkhodnaya (374 km long) (fig 2). Consequently, as a result of reducing the number of locomotive runs to three, two locomotive crew relief points will be reduced: in Artyshta II and in Irtyshskoye.

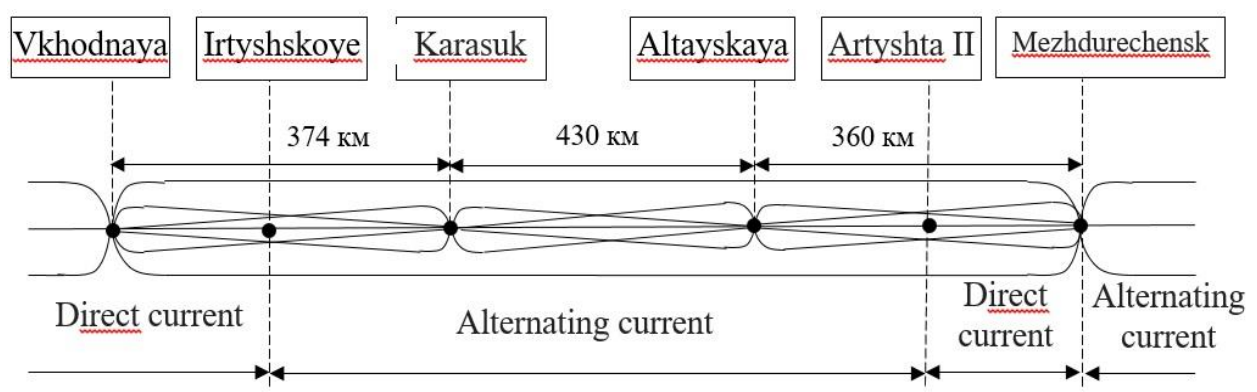

Fig. 2. Prospective scheme of locomotive runs for operation of dual-mode freight electric locomotives 2EV120 and locomotive crews at the operating domain Mezhdurechensk - Vkhodnaya.

To increase the efficiency of the transportation process and save money, at the electrified operating domain Mezhdurechensk - Vkhodnaya with a length of $1164 \mathrm{~km}$, where three stations for jointing two types of current are located, it is advisable to use innovative electric locomotives of a new generation of a $2 \mathrm{EV} 120$ series. As a result of their use at this operating domain, it is possible to reduce the fleet of locomotives in operation by about a third, the number of locomotive runs from five to three due to their lengthening, and the number of locomotive crew relief points from six to four, reduce the train travel time, increase technical and service speed, average daily mileage and average daily 
performance of the locomotive, the staff of locomotive crews, to increase the weight of trains, to reduce power consumption for traction.

\section{Conclusions}

On the basis of the calculations made, it is possible to assess the technological effects of the introduction into operation of the dual-mode freight electric locomotive 2EV120 at the Mezhdurechensk - Vkhodnaya operating domain in comparison with the currently operated locomotives.

After lengthening of the locomotive runs, due to the non-stop passing of the jointing stations, the average daily performance of locomotives will increase due to the exclusion of time for coupling, uncoupling and downtime at the station. The average daily mileage and service speed of freight trains will increase; electric power consumption for train traction will be reduced due to the absence of time spent on acceleration and braking. The expected effect in the area of accounting for specific electric power consumption for traction will be lower by $6-8 \%$ than for electric locomotives operating at the studied section.

\section{References}

1. B.M. Lapidus, N.A. Makhutov, OUS Bulletin 2, 1-21 (2017)

2. A.T. Osminin, OUS Bulletin 2, $42-57$ (2017)

3. S.V. Pokrovsky, Railway Equipment 3, 58-64 (2018)

4. A.S. Misharin, P.A. Kozlov, Railway Transport 4, 52-54 (2014)

5. P.A. Kozlov, I.O. Naboychenko, V.Yu. Permikin, Railway Transport 3, 26-29 (2016)

6. A.A. Zarovnyaev, I.O. Naboychenko, Railway Transport 7, 41-43 (2016)

7. E.N. Timukhina, V.Yu. Permikin, N.V. Kashcheeva, Transport of the Urals 1 (52), 4044 (2017)

8. A.V. Malakhov, V.Yu. Permikin, E.V. Vasiliev, Transport of the Urals, 2 (53), 32-36 (2017)

9. E.I. Begagoin, D.L. Khudoyarov, V.A. Kukushkin, Transport of the Urals 2(49), 105109 (2016)

10. A.A. Baklanov, N.V. Esin, A.P. Shilyakov, Proceedings of the third scientific and technical conference with international participation, Operational reliability of the locomotive fleet and improving the efficiency of train traction, 22-28 (2016)

11. V.Yu. Permikin, E.V. Vasiliev, A.V. Malakhov, A.Yu. Landyshev, V.A. Kukushkin, Transport of the Urals 3 (54), 41-48 (2017)

12. A.A. Baklanov, Theory of electric traction (2015)

13. S.V. Pokrovsky, Lokomotiv 7, 39 (2016)

14. S.V. Pokrovsky, Lokomotiv 2, 33-36 (2018)

15. O.S. Valinsky, Order Z-SIB TsT-108 (2017) 